DIW BERLIN

Discussion

Papers

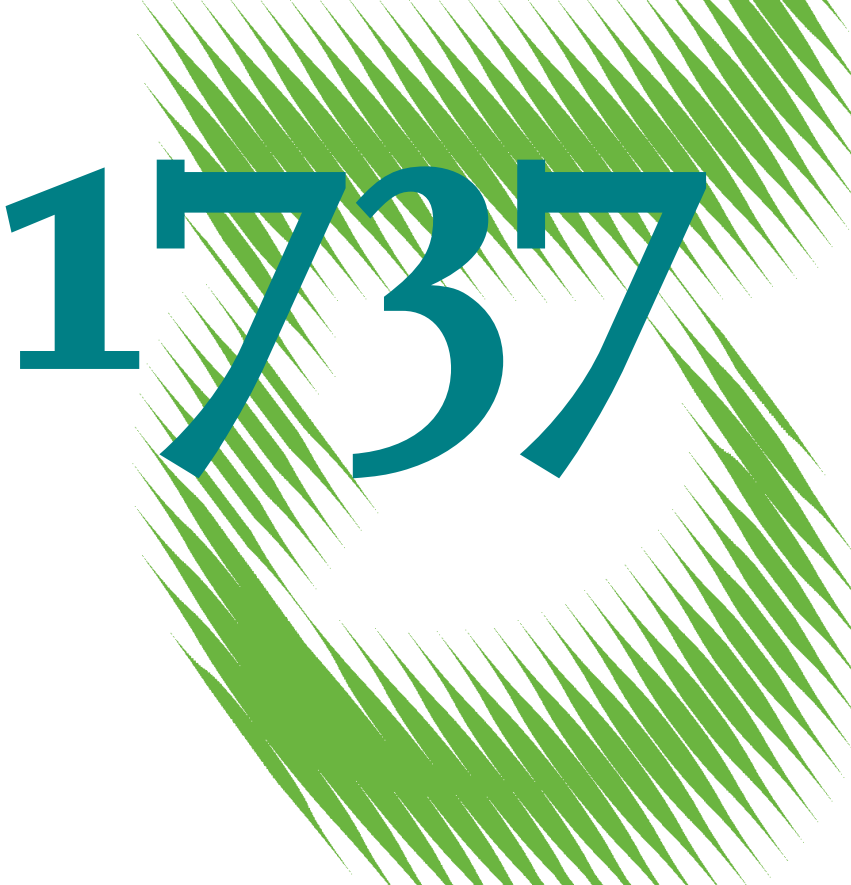

The Effects of Pricing Waste Generation: A Synthetic Control Approach 
Opinions expressed in this paper are those of the author(s) and do not necessarily reflect views of the institute.

IMPRESSUM

(C) DIW Berlin, 2018

DIW Berlin

German Institute for Economic Research

Mohrenstr. 58

10117 Berlin

Tel. +49 (30) $89789-0$

Fax +49 (30) $89789-200$

http://www.diw.de

ISSN electronic edition 1619-4535

Papers can be downloaded free of charge from the DIW Berlin website:

http://www.diw.de/discussionpapers

Discussion Papers of DIW Berlin are indexed in RePEc and SSRN:

http://ideas.repec.org/s/diw/diwwpp.html

http://www.ssrn.com/link/DIW-Berlin-German-Inst-Econ-Res.html 


\title{
The effects of pricing waste generation: A synthetic control approach
}

\author{
Matheus Bueno* and Marica Valente ${ }^{\dagger}$
}

\begin{abstract}
To internalize pollution externalities into household waste generation, Unit Pricing Systems (UPS) have been adopted worldwide. This paper evaluates the causal effects of a UPS on the disposal of municipal solid waste in Trento, Italy. To account for policy endogeneity due to unobservables, we employ the synthetic control method on a unique panel of monthly waste generation. Our results show that the policy was effective, with a significant decrease of the priced waste stream, unsorted waste, by $37.5 \%$. This effect seems to be largely driven by behavioral changes towards waste avoidance $(-8.6 \%)$ and a minor increase in recycling $(+6.1 \%)$.
\end{abstract}

Keywords: Waste generation, Unit pricing, Synthetic controls

JEL Codes: D01, C21, Q53

\footnotetext{
*Toulouse School of Economics, Toulouse, France. Email: matheus.bueno@tse-fr.eu.

$\dagger$ Corresponding author. Humboldt University of Berlin and German Institute for Economic Research (DIW Berlin), Berlin, Germany. Email: mvalente@diw.de, +49-30-89789-507.
} 


\section{Introduction}

The generation of Municipal Solid Waste (MSW) characterizes a classic example of negative externality, as its environmental and treatment costs are higher than its private ones. Standard flat fees on MSW collection, however, do not usually suffice for internalizing the increasing cost difference into individuals' waste generation behavior. Therefore, pricing waste per collected unit, a form of Pigouvian fee (Pigou, 1932), has been increasingly used as a policy instrument, known as Unit Pricing Systems (UPSs) or pay-as-you-throw programs. Existing empirical evaluations of such policies generally find them to be effective, when controlling for selection bias due to time-invariant (fixed) unobservables associated with their adoption $!^{1}$

Nevertheless, despite their growing popularity, there is an empirical gap on UPSs' effectiveness when the effects of waste generation's unobserved determinants vary over time, and on the behavioral mechanisms behind UPSs' effects. Using a unique data on monthly waste generation for nineteen municipalities in Italy between 2008 and 2016, this paper attempts to fill this gap by evaluating the causal effects of a UPS implemented on the disposal of unsorted MSW in the municipality of Trento in 2013.

The first contribution of this paper is to address the endogeneity associated with UPS adoption due to selection on unobservables. Waste generation behavior in municipalities adopting this policy may have unobserved determinants that spawn diverging waste generation trends with respect to municipalities not adopting it. This would invalidate identifying assumptions of standard policy evaluations based on differencing out fixed unobservables, such as with fixed effect and difference-in-differences estimators. In the attempt to account for unobserved determinants with potentially time-varying effects, we implement the Synthetic Control Method (SCM) Abadie and Gardeazabal, 2003; Abadie et al., 2010). This method reconstructs the counterfactual outcomes using a combination of untreated municipalities with similar outcome trajectories that did not select into treatment, hence replicating the unobserved heterogeneity. Several empirical appli-

\footnotetext{
${ }^{1}$ See, e.g., the survey in Huang et al. $(2011)$, and the literature review in Section 2 .
} 
cations in other areas of study have been implementing the $\mathrm{SCM}^{2}$, but, in the authors' best knowledge, this is the first paper doing so to evaluate waste pricing policies.

Secondly, this paper adds to the literature by studying the behavioral mechanisms behind the partial effects on the priced waste stream. When the relative price of unsorted waste increases, individuals may shift away from generating unsorted waste either by recycling more or by avoiding waste generation of any sort, e.g., by using less packaging. Thereby, this paper looks at which behavioral response prevails by evaluating policy causal effects also on total and recycling waste generation.

Results are of sizeable magnitude and indicate changes in waste generation behavior. Unsorted waste generation fell immediately after the UPS implementation and levelled off after around two years, with an average decrease of $37.5 \%$ in the post-treatment period. This partial effect seems to have been largely driven by waste avoidance and a relatively smaller increase in recycling, with total waste decreasing by $8.6 \%$ and recycling waste increasing by $6.1 \%$. Placebo tests show that the unsorted waste reduction is strongly significant, while weaker and no significance is found for the causal effects on total and recycling waste, respectively.

The remainder of the paper is organized as follows: Section 2 provides a brief review of the related literature on UPS, and discusses potential methodological shortcomings. Section 3 outlines the SCM used to estimate the policy causal effects under study. Background and data are described in Section 4 . Section 5 provides the results, and Section 6 concludes.

\section{Literature}

Starting in the 1970s, UPSs have been broadly implemented both in Asia and the United States, e.g., Japan, some US states, namely California and Michigan, and large cities as New York and Washington (Miranda and Bauer, 1996). By the mid-2000s, UPSs have been used in 30 of the 100 largest municipalities in the country as, e.g., Seattle and

\footnotetext{
${ }^{2}$ See, e.g., Abadie et al. (2015), Acemoglu et al. (2016), Billmeier and Nannicini (2013), Cavallo et al. (2013), and Pinotti (2015).
} 
Vancouver (Skumatz, 2008). Afterwards, UPS was adopted in many European countries, particularly Switzerland, the Netherlands, the northeastern area of Germany, Denmark and Italy.

Since the 1990s, following their implementation, UPSs effects have been extensively studied in the literature. Evaluations in the United States respond for a large chunk of the early and current literature (Fullerton and Kinnaman, 1996, 2000; Hong et al., 1993; Huang et al., 2011; Miranda and Bauer, 1996; Podolsky and Nestor, 1998; Reschovsky and Stone, 1994; Van Houtven and Morris, 1999). Studies for other regions have followed through for Korea (Hong and Adams, 1999; Kim et al., 2008), Japan (Usui, 2009; Usui and Takeuchi, 2014, Yamakawa et al., 2002), and the Netherlands (Allers and Hoeben, 2010; Dijkgraaf and Gradus, 2004; Linderhof et al., 2001). However, to the authors' knowledge this is one of the first UPS policies to be evaluated in Italy and Europe, except from the Dutch case and another study on Italy (Bucciol et al., 2015). The scarce empirical evidence on the effects of European UPSs lingers despite its increasing use in the region, and the EU mandate targeting both waste avoidance and diversion (European Environment Agency, 2009, 2013, European Union, 2008).

The literature, however, faces significant challenges in addressing the endogeneity of UPS adoption. This policy may be implemented in municipalities with higher environmentalawareness or, oppositely, where waste generation is so high that policy alternatives to standard flat fees need to be explored. Hence, policy adoption is not orthogonal to municipalities' observed and unobserved waste generation determinants. Part of the literature controls for observed determinants within a regression framework estimating price elasticities of waste demand, mostly found to be inelastic (see Huang et al., 2011, for a discussion of these studies). To the authors' knowledge, among this literature, only Fullerton and Kinnaman (2000) and Huang et al. (2011) explicitly take into account selection biases with instrumental variable approaches, and find a negative effect of UPS on unsorted waste as well as a positive effect on recycling.

More recently, other studies accounted for unobserved heterogeneity in difference-indifferences and fixed effects estimations, concluding UPSs to be effective in reducing un- 
sorted waste and increasing recycling (see, e.g., Dijkgraaf and Gradus, 2004, Van Houtven and Morris, 1999, Linderhof et al., 2001, and Allers and Hoeben, 2010). While this is an improvement over previous analyses, it is likely the case that unobserved determinants of waste generation do not only lead to level differences, but also to different trends over time. In this direction, recent methodological advancements, as the SCM employed in this paper, may allow to control for time-varying effects of the unobserved determinants.

Finally, the literature provides scant empirical evidence on the behavioral mechanisms behind the reduced-form estimated effects of UPS implementations. Theoretical studies point towards both monetary and non-monetary incentives as important determinants of household waste generation behavior: While recycling waste or avoiding its generation are associated with opportunity costs in terms of time and effort spent, its benefits involve not only saving eventual fees on waste disposal but also the psychological reward, aka "warm-glow", associated with environmentally friendly attitudes (??Bénabou and Tirole, 2003; Brekke et al., 2004; Jenkins et al., 2003; Kahn, 2007; Morris and Holthausen Jr. 1994; Thøgersen, 2006). Thus, the direction and relative strength of UPSs' effects likely varies with levels of intrinsic motivation, recycling and avoidance habits as well as socioeconomic characteristics such as education, income, and age. On the one hand, pricing waste per unit could lead to increased recycling and waste avoidance. On the other hand, waste generation may stagnate or even increase due to the crowd out of intrinsic motivations (Abbott et al., 2013; Bruvoll and Nyborg, 2003). This paper analyzes these behavioral responses empirically by estimating causal effects of UPS on all waste streams: unsorted, recycling, and total.

\section{Methodology}

Instead of differencing out fixed unobserved heterogeneity, the synthetic control method, introduced by Abadie and Gardeazabal (2003), attempts to replicate the unobserved heterogeneity by matching the observable characteristics predicting post-treatment outcomes of the treated unit to those of a convex combination of untreated units, denoted as a syn- 
thetic control. Abadie et al. (2010) argue, using a linear factor model, that matching on observed confounders and on a long set of pre-treatment outcomes is possible as long as unobserved and observed confounders are also matched. It remains to be verified for any particular application, however, to which extent this matching is achieved.

In this specific application, for $i=1, \ldots, J+1$ municipalities and $t=1, \ldots, T$ time periods with $T_{0}, 1 \leq T_{0}<T$, pre-UPS treatment periods, let $Y_{i t}^{N}$ be the waste generation of municipality $i$ in time $t$ in the absence of the UPS policy and $Y_{i t}^{U P S}$ be its waste generation if exposed to the policy. Without loss of generality, let the first municipality, $i=1$, be exposed to the policy intervention while the remaining $J$ municipalities are not. The policy causal effect to be estimated is given by the Treatment effect on the Treated, $T T_{t}=Y_{1 t}^{U P S}-Y_{1 t}^{N}$ for $t>T_{0}$, and the empirical challenge is to reconstruct the counterfactual $Y_{1 t}^{N}$, i.e., the waste generation outcome of the treated municipality after the intervention had it not been treated $3^{3}$ Once the counterfactual outcome, $\hat{Y}_{1 t}^{N}$, is estimated, the average causal effect of the policy, i.e., the Average Treatment effect on the Treated (ATT), is computed as $\frac{1}{T-T_{0}} \sum_{t>T_{0}}\left(Y_{1 t}-\hat{Y}_{1 t}^{N}\right)$.

The synthetic control method recreates this counterfactual with a convex combination of untreated municipalities, i.e., $\hat{Y}_{1, t>T_{0}}^{N}=\Sigma_{i \neq 1} w_{i}^{*} Y_{i, t>T_{0}}^{N}$, by choosing a vector of weights $W^{*}=\left\{w_{i}^{*}\right\}_{i \neq 1}$ through an optimization program. More specifically, let $\boldsymbol{H}=\left(\eta_{1}, \ldots, \eta_{T_{0}}\right)$ be a set of weights that generates a linear combination of pre-treatment waste generation outcomes $Y_{i}^{H}=\Sigma_{t=1}^{T_{0}} \eta_{t} Y_{i t}$ of a municipality $i$, and take $M$ of such combinations. Now, let $X_{1}$ be a $(L+M) \times 1$ predictor vector composed by all $M$ selected linear combinations of pre-treatment outcomes and $L$ observed waste generation determinants of the treated municipality, i.e., $L$ covariates. Finally, take $X_{0}$ to be a matrix of dimensions $(L+M) \times J$, in which each column is the equivalent of the $X_{1}$ vector for an untreated municipality $4^{4}$ Then, for the treated municipality, $W$ is chosen to minimize $\sqrt{\left(X_{1}-X_{0} W\right)^{\prime} V\left(X_{1}-X_{0} W\right)}$ subject to $w_{i} \geq 0, \forall i$ untreated municipalities, and $\Sigma_{i \neq 1} w_{i}=1$, where $V$ is a $(L+M) \times(L+M)$

\footnotetext{
${ }^{3}$ Note that, as usual, it is assumed that the intervention has no anticipation effects on the waste generation before its implementation in any of the $J+1$ cities, i.e. $Y_{i t}^{U P S}=Y_{i t}^{N}, \forall i$ and $t, 1 \leq t \leq T_{0}$; and that there are no spillovers from the intervention on waste outcomes of untreated municipalities, i.e. $Y_{i t}^{U P S}=Y_{i t}^{N} \forall t$ and $i>1$.

${ }^{4}$ In order to avoid interpolation biases the control group is limited to municipalities with similar observed covariates and pre-treatment outcomes.
} 
diagonal weighting matrix for each predictor variable in the matrices $X$.

Different specifications of the estimator are possible by changing which $M$ combinations of pre-treatment outcomes are used and how they are weighted, along with the $L$ observed covariates, in the matrix $V$. In this paper, as in Abadie and Gardeazabal (2003), we select a sole combination of pre-treatment outcomes, i.e. $M=1$, corresponding to their unweighted average, i.e. $Y_{i}^{H}=\frac{1}{T_{0}} \Sigma_{t=1}^{T_{0}} Y_{i t}$. The predictors weighting matrix $V$, in turn, is chosen, also as in Abadie and Gardeazabal (2003) and Abadie et al. (2010), among positive definite and diagonal matrices such that the Mean Squared Error (MSE) of the outcome is minimized for the pre-treatment periods.

Since this comparative case study setting is not suitable for large sample inferential techniques, placebo tests are performed by applying the SCM to each control municipality in the sample. If the estimated treatment effect in the treated municipality is large relative to the one estimated for a control municipality chosen at random, it is possible to conclude that the UPS policy had a significant impact on waste generation in the treated municipality. Placebo tests are also performed in a restricted sample of control units for which the estimated synthetic controls provide a better pre-treatment fit, in the form of a lower MSE than the actual treated unit. Finally, the probability of finding treatment effects as high as in the treatment unit is reported as $\frac{\sum_{j=2}^{J+1} \mathbf{1}\left(\frac{1}{T-T_{0}} \sum_{t>T_{0}} T T_{t j} \geq \frac{1}{T-T_{0}} \sum_{t>T_{0}} T T_{t 1}\right)}{J+1}$.

Lastly, in order to illustrate the methodological innovation with respect to the previous UPS literature, the SCM results are compared to the ones obtained through the conventional Difference-In-Differences (DID) approach. For this, the same $L$ covariates specified in the matrices $X$ above are used to estimate the ATT. Finally, the bias of the DID estimator is evidenced by showing that the parallel trend assumption fails in the pre-treatment period.

\section{Background and Data}

The UPS policy here analyzed was implemented in Trento, Italy, in January 2013. Before this date, each household paid a yearly flat fee for MSW collection under a door-to-door- 
pick-up system. The policy consists of adding, on top of this flat fee, a unit price of $€ 0.09$ per liter of unsorted waste. Starting from January 2013, each household was mandated to discard its unsorted waste either in 30 liter distinctively marked waste bags that cost $€ 2.69$ each or, in buildings with a maximum of four flats and single houses, in 120 liter waste bins equipped with a coded microchip that is activated at every emptying of the bin at the price of $€ 10.8$. To avoid free riding problems, every building's bin is locked. If non-compliant bags are found, the whole building is charged for the offense to guarantee self-enforcing and mutual monitoring among residents (see, e.g., Reschovsky and Stone, 1994).

We collected monthly data on waste generation, $Y$, between January 2008 and December 2016 for nineteen Italian municipalities in different regions: Trento - the treated city-, Bari, Benevento, Bergamo, Brindisi, Chivasso, Ciriè, Collegno, Milano, Moncalieri, Novara, Pesaro, Pinerolo, Rivoli, Salerno, Settimo Torinese, Taranto, Torino, and Venaria Reale. MSW data for the region of Piedmont, Apulia, and Campania are collected from the respective regional observatory on municipal wast 5 , while MSW data of Trento come from the official website of the municipality ${ }^{6}$. For the other municipalities, MSW data was provided upon request either by the regional environmental protection agency (ARPA - Pesaro) or by the waste collection company (A2A Bergamo, AMSA Milano, and ASSA Novara).

The outcome variables of interest are the three waste streams measured as log per capita kilograms of unsorted waste $(\ln U W)$, recycling waste $(\ln R W)$, and total waste $(\ln T W)$.7 The covariates determining waste generation were chosen by literature review, and represent socio-economic predictors of waste generation and recycling habits. 8 These are: average household size (hhSize); log per capita income in thousand euros (lnIncome); income inequality, as measured by the Gini coefficient (Gini); educational attainment,

\footnotetext{
${ }^{5}$ respectively, www.cittametropolitana.torino.it, www.sit.puglia.it, www.mysir.it.

${ }^{6}$ www.comune.trento.it.

${ }^{7}$ Under recycling waste it is meant the gross recycling stream arriving to the recycling facility before additional sorting. Moreover, in the aggregation of total recycling amounts, we did not correct the high seasonality of sub-streams (e.g., green waste), as this seasonality is common to all cities.

${ }^{8}$ See, e.g., Grossmann et al. (1974); Jenkins et al. (2003); Miranda and Bauer (1996); Richardson and Havlicek (1978); Van Houtven and Morris (1999), and Wertz (1976).
} 
measured as the share of the population with a graduate degree or higher (college); tourism intensity, measured as the nights spent by tourists divided by the local population (tourism); and age structure, decomposed into citizens under $15($ age $<15)$ and over 65 years old $(a g e>65)$. This data was obtained from the Italian National Institute of Statistics (Istat), as well as Comuni-Italiani.it and Tuttitalia.it.

Importantly for the synthetic control method, the values of waste generation outcomes and predictors of the treated municipality have to lie within the convex hull spanned by the control municipalities' values, such that a convex combination of control municipalities can fit the actual treated municipality. Figure 1 presents evidence on the presence of such common support.

Figure 1: Data Descriptives: Boxplots of Mean-corrected Variables

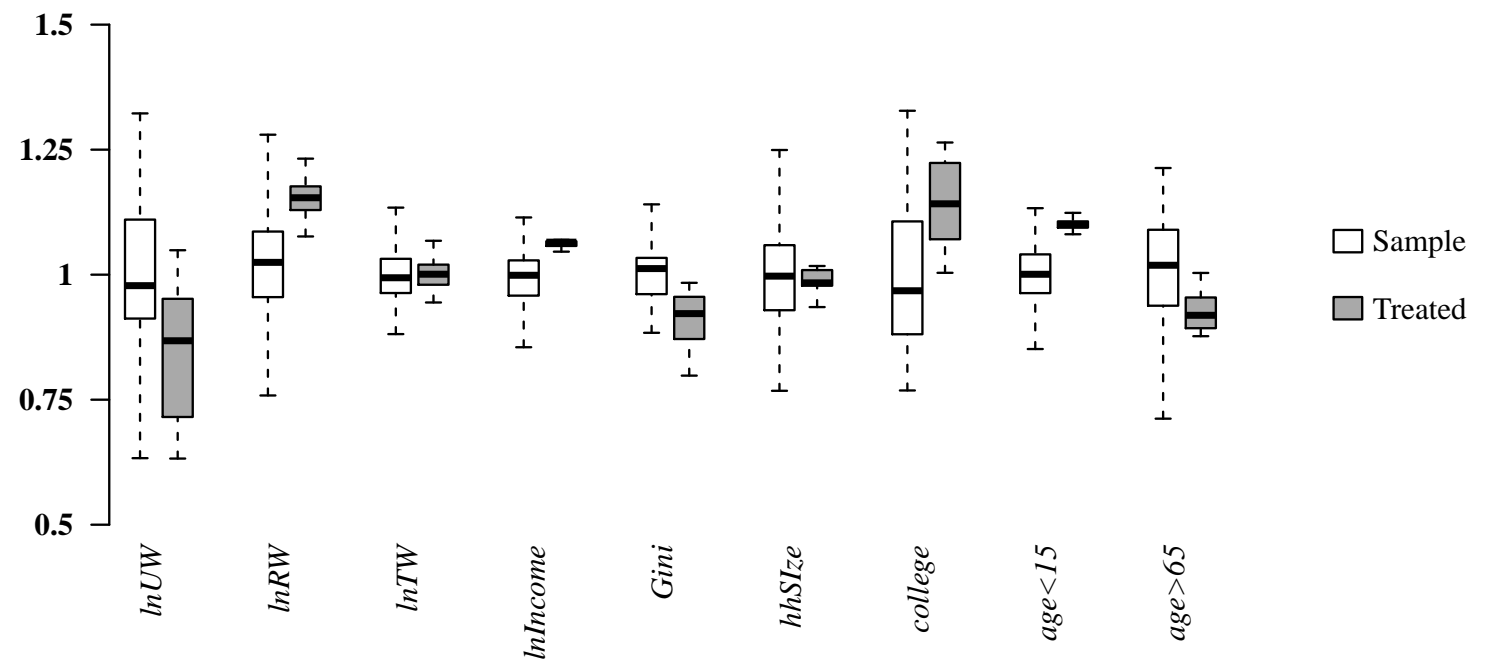

\section{Results}

Using the SCM, we estimate the counterfactual, aka synthetic Trento, as a linear combination of outcomes of the $J$ control municipalities. Thereby, we estimate optimal weights, $\left\{w_{i}^{*}\right\}_{i \neq 1}$, for each waste stream separately. 
Table 1: Synthetic Trento: Estimated Weights for Control Units

\begin{tabular}{lccclccc}
\hline \hline Control Units & UW & RW & TW & Control Units & UW & RW & TW \\
\hline Bari & 0 & 0 & 0 & Novara & 0.645 & 0.559 & 0.006 \\
Benevento & 0.058 & 0 & 0.001 & Pinerolo & 0 & 0 & 0 \\
Bergamo & 0 & 0.217 & 0.536 & Pesaro & 0.291 & 0.224 & 0.073 \\
Brindisi & 0 & 0 & 0 & Rivoli & 0 & 0 & 0.001 \\
Collegno & 0 & 0 & 0.002 & Salerno & 0 & 0 & 0 \\
Chivasso & 0.001 & 0 & 0.363 & Settimo Torinese & 0 & 0 & 0.001 \\
Ciriè & 0 & 0 & 0.012 & Taranto & 0 & 0 & 0 \\
Milano & 0 & 0 & 0 & Torino & 0 & 0 & 0.001 \\
Moncalieri & 0 & 0 & 0.001 & Venaria Reale & 0.005 & 0 & 0.003 \\
\hline
\end{tabular}

Table 1 reports the estimated weights. The control cities of Novara and Pesaro best resemble Trento in terms of unsorted waste (UW); Novara, Pesaro, and Bergamo in terms of recycling (RW); Bergamo and Chivasso in terms of total waste (TW). The SCM provides unbiased counterfactual estimates if predictor variables as well as outcomes of the treated unit are sufficiently close to those of the synthetic unit pre-treatment. Table 2 shows that, compared to the sample average assigning equal weights to all control units, synthetic Trento is most similar to Trento in terms of outcomes and predictor averages, and it has a lower MSE for each waste type. 
Table 2: Outcome and Predictor Means (2008-2012)

\begin{tabular}{|c|c|c|c|c|c|}
\hline$Y: \ln U W$ & Treated & Synthetic & Sample & $Y: \ln R W$ & Treated \\
\hline $\ln U W$ & 2.735 & 2.741 & 3.049 & $\ln R W$ & 3.310 \\
\hline $\ln R W$ & 3.270 & 3.257 & 2.811 & $\ln U W$ & 2.819 \\
\hline hhSize & 2.892 & 2.770 & 2.709 & hhSize & 2.243 \\
\hline lnIncome & 2.847 & 2.734 & 2.664 & lnIncome & 2.892 \\
\hline Gini & 0.274 & 0.299 & 0.309 & Gini & 0.274 \\
\hline tourism & 4.736 & 4.245 & 2.237 & tourism & 4.736 \\
\hline age $<15$ & 0.144 & 0.128 & 0.129 & age $<15$ & 0.144 \\
\hline age $>65$ & 0.197 & 0.218 & 0.213 & age $>65$ & 0.197 \\
\hline college & 0.117 & 0.115 & 0.101 & college & 0.117 \\
\hline \multirow[t]{11}{*}{ MSE } & & 0.029 & 0.732 & MSE & \\
\hline & & $Y: \ln T W$ & Treated & Synthetic & Sample \\
\hline & & $\ln T W$ & 3.758 & 3.759 & 3.721 \\
\hline & & hhSize & 2.243 & 2.146 & 2.280 \\
\hline & & lnIncome & 2.892 & 2.876 & 2.709 \\
\hline & & Gini & 0.274 & 0.296 & 0.309 \\
\hline & & tourism & 4.736 & 3.465 & 2.237 \\
\hline & & age $<15$ & 0.144 & 0.117 & 0.129 \\
\hline & & age $>65$ & 0.197 & 0.205 & 0.213 \\
\hline & & college & 0.117 & 0.112 & 0.101 \\
\hline & & MSE & & 0.203 & 0.785 \\
\hline
\end{tabular}

To show the outcome fit in each time period, Figure 2 plots waste time series for Trento (solid) and synthetic Trento (dotted), and a vertical dotted line that separates pre- from post-treatment periods in time zero (January 2013). 
Figure 2: UW, TW, RW Time Series for Trento (solid) and Synthetic Trento (dotted)

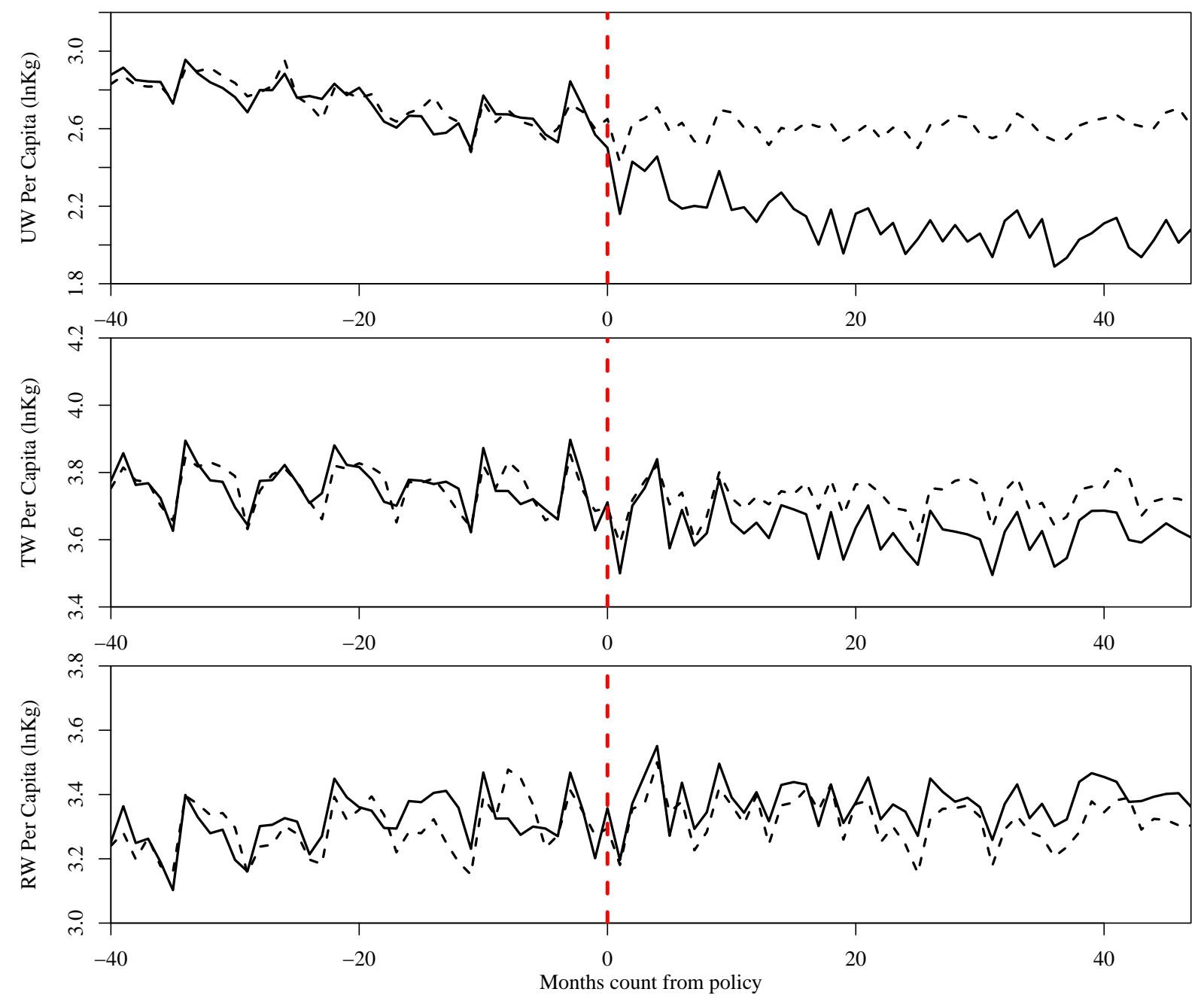

The behavior of the treated outcome and its counterfactual results to be very similar in the pre-treatment period. This suggests that counterfactuals capture treated-specific unobserved heterogeneity in waste generation, which indicates unbiasedness of the synthetic control estimators. As for the post-treatment period, Figure 2 displays the waste paths and gaps between treated and synthetic unit $9^{9}$ For UW, we observe a large and persistent divergence between Trento's UW path and its counterfactual. While the latter remains fairly stable over time, the former drops immediately after policy, and levels off in the long-run. The ATT, computed as the average post-treatment percent gap, amounts to 37.5\%. For TW, post-treatment gaps are negative, and of moderate magnitude at first,

${ }^{9}$ The sum of the counterfactual UW and RW should approximately equal the counterfactual TW. This is indeed the case, with a negligible overestimation of TW post-treatment by $0.4 \%$ on average. 
but then increasing in the longer-run. In particular, the treated outcome decreases to a lower level after about one year from the policy implementation, while the counterfactual level stays constant over time. The negative ATT amounts to 8.6\%. For RW, we observe mostly positive post-treatment gaps, though of very small magnitude, and increasing only after about two years from the policy. Further, both the treated outcome and its counterfactual follow a positive trend, indicating overall increasing trends in recycling habits. Therefore, the ATT for RW which amounts to $6.1 \%$ is likely due to national trends, and not to the policy.

To assess the statistical significance of the gaps found, placebo tests are performed by applying the synthetic control method to each control municipality in the sample. Figure 3 plots gaps for the treated unit (black) and placebo control units (grey) against their respective synthetic estimate (x-axis) ${ }^{10}$

\footnotetext{
${ }^{10}$ We exclude the treated unit from placebo counterfactual estimation because it self-selected into the policy. Additionally, counterfactuals with a pre-treatment MSE five times higher than the treated unit's MSE are discarded to safeguard against out-of-support estimations (Abadie et al. 2010).
} 
Figure 3: Placebo Tests: Trento (black line) and Control Units (grey lines)

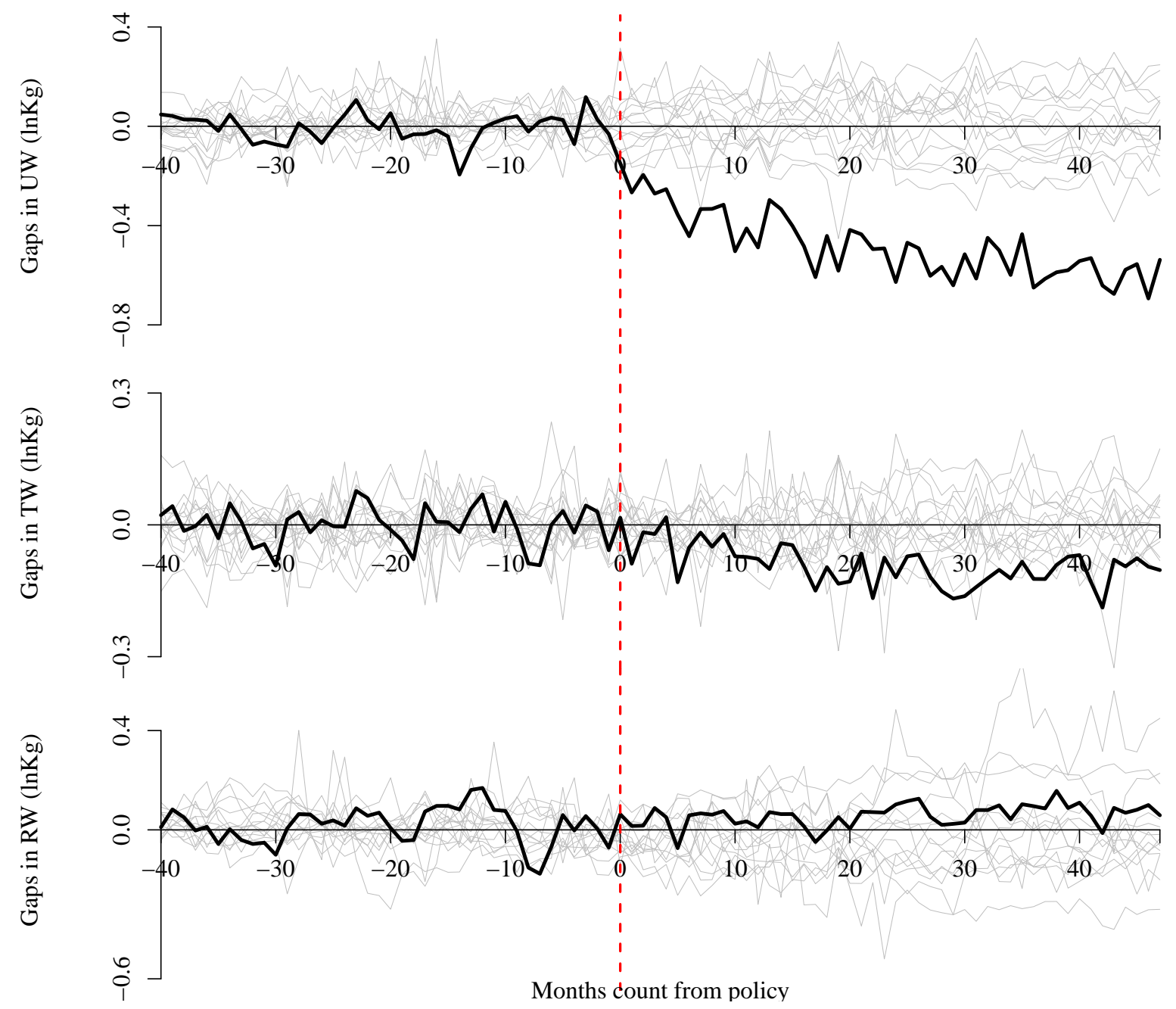

For UW and TW, the estimated ATT for the treated unit is the largest in absolute terms over the other 16 placebo ATT estimates, however, this does not hold for RW. Thereby, placebo tests indicate that the policy has a statistically significant impact on UW and TW, but not on RW. A second way to account for pre-treatment goodness of fit is to compare the distribution of the ratio of post- and pre-treatment MSE for treated and placebo units (Abadie et al., 2010). Finally, since the MSE criterion overweights large discrepancies, the ATT of each unit is also plotted, for robustness, against its pretreatment Mean relative Absolute Deviation (MAD), the pre-treatment average percent gap between treated and synthetic outcomes (Seifert and Valente, 2017). 
Figure 4: MSE Ratio and ATT-MAD Tests for Trento (black) and Control Units (white)
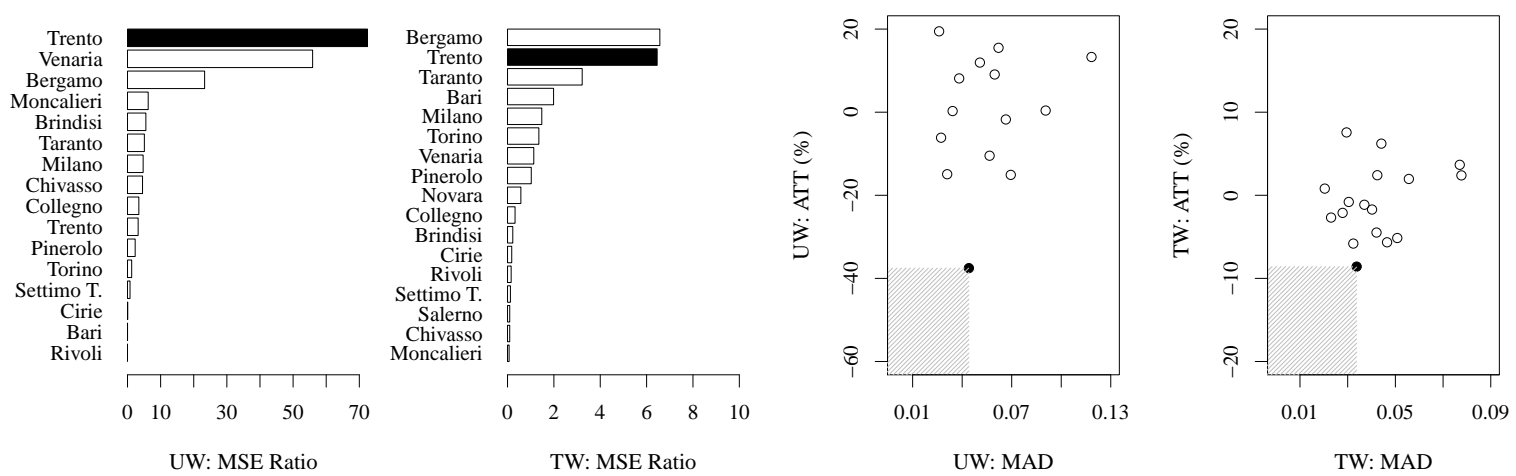

Table 4 plots the MSE ratio test and the ATT-MAD test for UW and TW. MSE ratio tests show that the treated unit has the largest, and second largest MSE ratio for UW and TW, respectively. The policy effect, hence, seems to be significant on UW and not largely on TW. Nevertheless, since no control unit shows a higher ATT as well as a smaller MAD than the treated unit, ATT-MAD tests suggest statistical significant causal effects for both UW and TW.

The statistically significant effect of the policy, stronger on UW, and weaker on TW, may be explained by changes in waste generation behaviors of households due to the policy. As intended by the policy, households decreased priced waste generation. Furthermore, reductions in TW occurring especially in the long-run suggest behavioral adjustments towards waste avoidance. This behavioral response can be also explained by increased reuse opportunities as, e.g., many supermarkets started providing facilities for refilling of beverages and detergents. Causal effects on RW, on the other hand, are not significant. This is likely due to two reasons: First, the presence of increasing national trends. Second, casual evidence from the waste collection companies suggests the policy to have enhanced households' recycling performance, through, e.g., buying lighter packages for the same products.

In conclusion, the SCM estimates suggest that the policy was effective on the priced waste, and further caused households to avoid waste generation, likely as a consequence of pro-environmental changes in waste generation behavior. However, the policy did not cause households to significantly substitute priced waste with recycling. Concerning negative side effects of the policy, illegal dumping of waste could have happened, although 
the municipality's administration reported only minor episodes of illegal dumping.

Finally, in order to compare our empirical strategy with the previous literature, we estimate policy effects using the conventional DID approach. Table 3 reports estimates accounting for possible dependence in the residuals using Driscoll and Kraay (1994) adjustment 11

Table 3: DID Regression Estimates (2008-2016) for UW, RW and TW (lnKg)

\begin{tabular}{|c|c|c|c|}
\hline & $\ln U W$ & $\ln R W$ & $\ln T W$ \\
\hline lnIncome & $\begin{array}{l}-0.233 \\
(0.308)\end{array}$ & $\begin{array}{l}-0.443^{* *} \\
(0.210)\end{array}$ & $\begin{array}{l}-0.416^{* * *} \\
(0.099)\end{array}$ \\
\hline Gini & $\begin{array}{l}-7.169^{* * *} \\
(1.165)\end{array}$ & $\begin{array}{l}2.408 \\
(1.749)\end{array}$ & $\begin{array}{l}-3.638^{* * *} \\
(0.194)\end{array}$ \\
\hline tourism & $\begin{array}{l}0.046^{* * *} \\
(0.011)\end{array}$ & $\begin{array}{l}0.003 \\
(0.006)\end{array}$ & $\begin{array}{l}0.029^{* * *} \\
(0.006)\end{array}$ \\
\hline age $<15$ & $\begin{array}{l}0.057^{* * *} \\
(0.021)\end{array}$ & $\begin{array}{l}-0.184^{* * *} \\
(0.018)\end{array}$ & $\begin{array}{l}-0.020^{* *} \\
(0.008)\end{array}$ \\
\hline age $>65$ & $\begin{array}{l}0.008 \\
(0.019)\end{array}$ & $\begin{array}{l}0.079^{* * *} \\
(0.013)\end{array}$ & $\begin{array}{l}0.028^{* * *} \\
(0.006)\end{array}$ \\
\hline college & $\begin{array}{l}-0.189^{* * *} \\
(0.025)\end{array}$ & $\begin{array}{l}0.184^{* * *} \\
(0.015)\end{array}$ & $\begin{array}{l}-0.034^{* *} \\
(0.016)\end{array}$ \\
\hline treated & $\begin{array}{l}-0.316^{* * *} \\
(0.120)\end{array}$ & $\begin{array}{l}0.687^{* * *} \\
(0.071)\end{array}$ & $\begin{array}{l}0.055 \\
(0.040)\end{array}$ \\
\hline post & $\begin{array}{l}0.216^{*} \\
(0.117)\end{array}$ & $\begin{array}{l}-0.543^{* * *} \\
(0.106)\end{array}$ & $\begin{array}{l}-0.095^{* *} \\
(0.046)\end{array}$ \\
\hline$A T T$ & $\begin{array}{l}-0.555^{* * *} \\
(0.057)\end{array}$ & $\begin{array}{l}0.012 \\
(0.061)\end{array}$ & $\begin{array}{l}-0.076^{* * *} \\
(0.024)\end{array}$ \\
\hline Constant & $\begin{array}{l}9.348^{* * *} \\
(0.504)\end{array}$ & $\begin{array}{l}4.583^{* * *} \\
(0.594)\end{array}$ & $\begin{array}{l}8.413^{\text {*** }} \\
(0.114)\end{array}$ \\
\hline Time effects & Yes & Yes & Yes \\
\hline F Statistic & $29.90^{* * *}$ & $12.81^{* * *}$ & $16.56^{* * *}$ \\
\hline Adjusted $\mathrm{R}^{2}$ & 0.478 & 0.464 & 0.559 \\
\hline
\end{tabular}

Control variable estimates present overall plausible signs and magnitudes. In particular, we find that higher income municipalities produce less total and recycling waste,

\footnotetext{
${ }^{11}$ Note that while waste outcomes are measured monthly, covariates are measured annually, which is consistent with SCM application. For DID, however, we measure all dependent and independent variables annually. Further, hhSize is excluded due to multicollinearity, and age $<15$ is used as a proxy.
} 
with wealthier households potentially having higher opportunity costs of recycling and being overall less incline to public good provision (Magnani, 2000). In addition, the income inequality measure (Gini) negatively correlates with unsorted and total waste, possibly because income inequality is increasing in most cities, and at country-level, while waste streams are progressively diminishing. In addition, cities with more nights spent by tourists per inhabitant (tourism) produce more UW and TW, likely because tourists have less incentives to avoid waste and recycle. We also find that older cities $($ age $>65)$ recycle more and produce more waste in total, while cities with on average larger families $($ age $<15)$ generates less total waste, likely because they buy in bulk; they also recycle less and produce more unsorted waste as a possible consequence of more stringent time constraints, and higher opportunity costs of recycling. Then, higher-educated cities (college) produce less waste and recycle more, suggesting that higher education could proxy for higher environmental awareness levels.

Concerning the estimates of the policy average causal effect, we obtain a statistically significant negative ATT of about $55 \%$ for UW, and $7.6 \%$ for TW, and, as with SCM estimates, no statistically significant ATT for RW. Potential violation of the DID Parallel Trend Assumption (PTA) for UW and TW is assessed by in-time placebo tests (Autor, 2003). Figure 5 plots the estimated ATTs post-treatment (black) and placebo pre-treatment (white) for each year with their respective confidence interval.

Figure 5: In-time Placebos: Pre- (white) and Post-treatment (black) Policy Effects
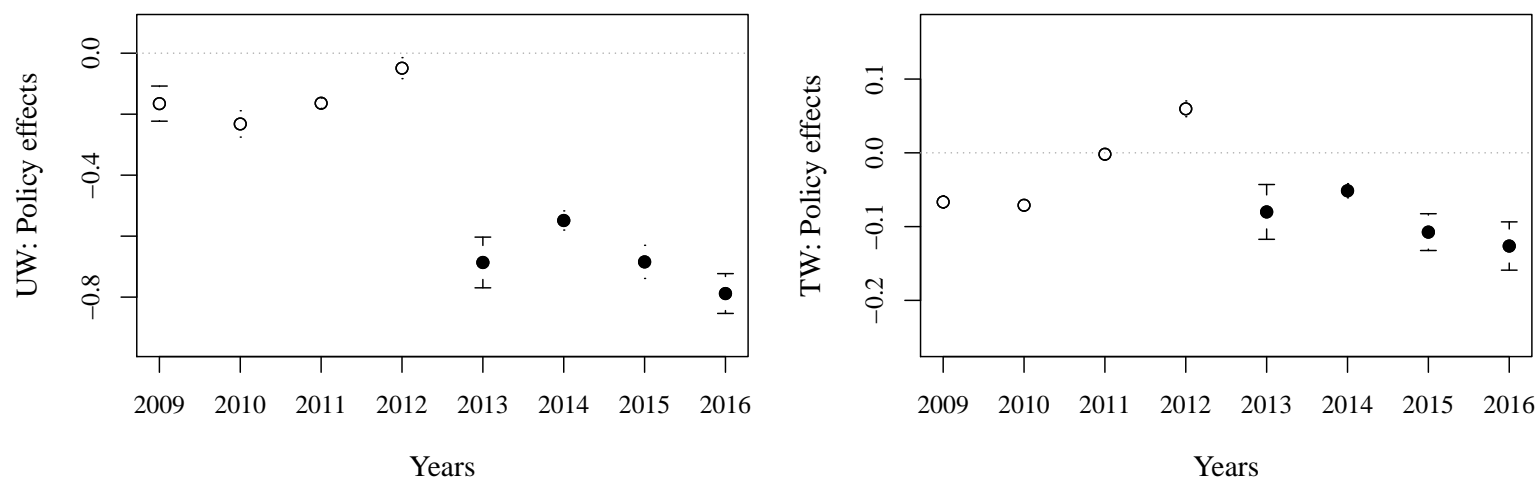

For UW and TW, pre-treatment effects are jointly statistically significant at the $1 \%$ 
and $10 \%$ level, respectively, indicating a failure of the PTA assumed in the DID regression model. Thus, we find the SCM to be better suited for the current policy causal evaluation, due to its ability to account for possible time-varying effects of unobserved determinants of waste generation.

\section{Conclusions}

This paper evaluates the effects of a Unit Pricing System (UPS) implemented in Trento, Italy, in 2013, on the disposal of municipal solid waste. To account for time-varying effects of unobserved determinants of waste generation, we use the synthetic control method (Abadie and Gardeazabal, 2003, Abadie, Diamond, and Hainmueller, 2010), in which the counterfactual outcome of the treated municipality is reconstructed with a convex combination of untreated municipalities with similar outcome trajectories but not selecting into treatment.

Using a unique data on monthly waste generation for nineteen municipalities in Italy over the period 2008-2016, we find that UPS was effective, and caused changes in household waste generation behavior. In particular, households responded by reducing priced waste, i.e., unsorted waste, by $37.5 \%$ on average in the post-treatment period. This partial causal effect seems to have been driven by waste avoidance and, to a lesser extent, by increased recycling. In fact, our results show that total waste decreases by $8.6 \%$ on average after policy, and recycling increases by $6.1 \%$. The statistical significance of the results, found to be stronger on unsorted waste, and weaker on total waste, may be ex-

plained by changes in waste generation behaviors of households after policy. As intended, households were induced to decrease the generation of the priced waste and sustain increasing recycling levels. However, the policy did not cause households to significantly substitute priced waste by recycling.

These findings are useful for the policy debate on which policy instrument can be adopted for municipal waste reduction. We find strong evidence that monetary incentives are effective to induce behavioral changes in household waste generation. These results 
show that unit pricing systems may help applying EU's waste management principles, and partly internalize negative externalities of waste generation. Further research should assess the optimality of the unit price, and the estimation of environmental benefits as well as private savings due to waste reductions induced by UPS policies.

\section{Acknowledgements}

We thank Manuel Arellano, Sylvain Chabé-Ferret, Jacint Enrich, Bernd Fitzenberger, Yinghua He, Thierry Magnac, Roberto Renó, and Stefan Seifert for fruitful discussion and input. The paper was presented at the conferences of the Italian Association of Environmental and Resource Economists (IAERE, Rome), Econometrics of Panel Data and Network Analysis Summer School (CRC, Berlin), European University Institute (FSR, Florence), and the Italian Workshop on Econometrics and Empirical Economics (IWEEE, Milan).

\section{References}

Abadie, A., A. Diamond, and J. Hainmueller (2010). Synthetic control methods for comparative case studies: Estimating the effect of California's tobacco control program. Journal of the American Statistical Association 105(490), 493-505.

Abadie, A., A. Diamond, and J. Hainmueller (2015). Comparative politics and the synthetic control method. American Journal of Political Science 59(2), 495-510.

Abadie, A. and J. Gardeazabal (2003). The economic costs of conflict: A case study of the Basque country. American Economic Review 93(1), 113-132.

Abbott, A., S. Nandeibam, and L. O'Shea (2013). Recycling: Social norms and warmglow revisited. Ecological Economics 90, 10-18.

Acemoglu, D., S. Johnson, A. Kermani, J. Kwak, and T. Mitton (2016). The value of connections in turbulent times: Evidence from the United States. Journal of Financial Economics 121(2), 368-391.

Allers, M. and C. Hoeben (2010). Effects of unit-based garbage pricing: A differences-indifferences approach. Environmental Resource Economics 45(3), 405-28.

Autor, D. (2003). Outsourcing at will: The contribution of unjust dismissal doctrine to the growth of employment outsourcing. Journal of Labor Economics 21(1), 1-42. 
Bénabou, R. and J. Tirole (2003). Intrinsic and extrinsic motivation. The Review of Economic Studies 70(3), 489-520.

Billmeier, A. and T. Nannicini (2013). Assessing economic liberalization episodes: A synthetic control approach. The Review of Economics and Statistics 95(3), 983-1001.

Brekke, K., S. Kverndokk, and K. Nyborg (2004). An economic model of moral motivation. Journal of Public Economics 87(9-10), 1967-1983.

Bruvoll, A. and K. Nyborg (2003). The cold shiver of not giving enough: On the social cost of recycling campaigns. Land Economics 80(4), 539-549.

Bucciol, A., N. Montinari, and M. Piovesan (2015). Do not trash the incentive! monetary incentives and waste sorting. The Scandinavian Journal of Economics 117(4), 12041229 .

Cavallo, E., S. Galiani, I. Noy, and J. Pantano (2013). Catastrophic natural disasters and economic growth. The Review of Economics and Statistics 95(5), 1549-1561.

Dijkgraaf, E. and R. H. J. M. Gradus (2004). Cost savings in unit-based pricing of household waste: The case of The Netherlands. Resource and Energy Economics 26(4), $353-371$.

Driscoll, J. C. and A. C. Kraay (1994). Consistent covariance matrix estimation with spatially dependent panel data. Review of Economics and Statistics 80(4), 549-560.

European Environment Agency (2009). Diverting waste from landfill. Effectiveness of waste management policies in the European Union. Report No 7/2009.

European Environment Agency (2013). Managing municipal solid waste - A review of achievements in 32 European countries. Report No 2/2013.

European Union (2008). Directive 2008/98/EC of the european parliament and of the council of 19 November 2008 on waste and repealing certain directives. Official Journal of the European Union 22/11/2008, 3-30.

Fullerton, D. and C. T. Kinnaman (1996). Household responses to pricing garbage by the bag. The American Economic Review 86(4), 971-984.

Fullerton, D. and C. T. Kinnaman (2000). Garbage and recycling with endogenous local policy. Journal of Urban Economics 48(3), 419-442.

Grossmann, D., J. F. Hudson, and D. Marks (1974). Waste generation models for solid waste collection. Journal of the Environmental Engineering Division 100(6), 1219 1230 .

Hong, S. and R. M. Adams (1999). Household responses to price incentives for recycling: Some further evidence. Land Economics 75(4), 505-14.

Hong, S., R. M. Adams, and H. A. Love (1993). An economic analysis of household recycling of solid wastes: The case of Portland, Oregon. Journal of Environmental Economics and Management 25(2), 136-46. 
Huang, J.-C., J. M. Halstead, and S. B. Saunders (2011). Managing municipal solid waste with unit-based pricing: Policy effects and responsiveness to pricing. Land Economics 87(4), 645-660.

Jenkins, R. R., S. A. Martinez, K. Palmer, and M. J. Podolsky (2003). The determinants of household recycling: A material-specific analysis of recycling program features and unit pricing. Journal of Environmental Economics and Management 45(2), 294-318.

Kahn, M. (2007). Do greens drive hummers or hybrids? Environmental ideology as a determinant of consumer choice. Journal of Environmental Economics and Management 54(2), 129-145.

Kim, G. S., Y. J. Chang, and D. Kelleher (2008). Unit pricing of municipal solid waste and illegal dumping: An empirical analysis of Korean experience. Environmental Economics and Policy Studies 9(3), 167-176.

Linderhof, V., P. Kooreman, M. Allers, and D. Wiersma (2001). Weight-based pricing in the collection of household waste: The Oostzaan case. Resource and Energy Economics 23(4), 359-371.

Magnani, E. (2000). The Environmental Kuznets Curve, environmental protection policy and income distribution. Ecological Economics 32(3), 431-443.

Miranda, M. L. and S. Bauer (1996). The urban performance of unit pricing: An analysis of variable rates for residential garbage collection in urban areas. The U.S. Environmental Protection Agency. Report prepared for the Office of Policy, Planning, and Evaluation.

Morris, G. E. and D. M. Holthausen Jr. (1994). The economics of household solid waste generation and disposal. Journal of Environmental Economics and Management 26(3), $215-234$.

Pigou, A. C. (1932). Divergences between marginal social net product and marginal private net product. The Economics of Welfare Part II, Chapter IX.

Pinotti, P. (2015). The economic costs of organized crime: Evidence from southern Italy. The Economic Journal 125(586), 203-232.

Podolsky, M. J. and D. V. Nestor (1998). Assessing incentive based environmental policies for reducing household waste disposal. Contemporary Economic Policy 16(4), 27-39.

Reschovsky, J. D. and S. E. Stone (1994). Market incentives to encourage household waste recycling: Paying for what you throw away. Journal Of Policy Analysis and Management 13(1), 120-39.

Richardson, R. A. and J. H. Havlicek (1978). Economic analysis of the composition of household solid wastes. Journal of Environmental Economics and Management 5(1), $103-111$.

Seifert, S. and M. Valente (2017). An offer that you can't refuse? Agrimafias and migrant labor on vineyards in southern Italy. Unpublished manuscript, DIW Berlin. 
Skumatz, L. (2008). Pay as you throw in the U.S.: Implementation, impacts, and experience. Waste Management 28(12), 2778-2785.

Thøgersen, J. (2006). Norms for environmentally responsible behaviour: An extended taxonomy. Environmental Psychology 26(4), 247-261.

Usui, T. (2009). Does a rebound effect exist in solid waste management? Critical Issues in Environmental Taxation 7, 413-422.

Usui, T. and K. Takeuchi (2014). Evaluating unit-based pricing of residential solid waste: A panel data analysis. Environmental and Resource Economics 58(2), 245-271.

Van Houtven, G. L. and G. E. Morris (1999). Household behavior under alternative pay-as-you-throw systems for solid waste disposal. Land Economics 75(4), 515-537.

Wertz, K. L. (1976). Economic factors influencing households' production of refuse. Journal of Environmental Economics and Management 2(4), 263-272.

Yamakawa, H., K. Ueta, and Y. Terashima (2002). Factors influencing illegal dumping in communities with variable rate programs. Journal of the Japan Society of Waste Management Experts 13(4), 419-427. 